\title{
Anti-inflammatory and antioxidant activity of salicylic acid conjugated dihydropyrazoline analogues
}

\author{
Naveen Puttaswamy ${ }^{1,2}$, Rekha N D ${ }^{3}$, Lakshmi Ranganatha $V^{4}$, Prashanth $T^{1,2}$, Shaukath Ara Khanum ${ }^{2 *}$ \\ ${ }^{1}$ Department of Chemistry, JSS College of Arts, Commerce \& Science, Ooty Road, Mysuru - 570025. \\ ${ }^{2}$ Department of Chemistry, Yuvaraja's College, University of Mysore, Mysuru - 570005. \\ ${ }^{3}$ Department of Biotechnology, JSS College of Arts, Commerce \& Science, Ooty Road, Mysuru - 570025. \\ ${ }^{4}$ Department of Chemistry, The National Institute of Engineering, Mysuru - 570015.
}

\begin{tabular}{l}
\hline ARTICLE INFO \\
\hline Article history: \\
Received on: $25 / 10 / 2017$ \\
Accepted on: 19/01/2018 \\
Available online: $27 / 02 / 2018$ \\
\\
\hline Key words: \\
1,3-dipolar cycloaddition, \\
anti-inflammatory, anti-oxi- \\
dant, phospholipase A2.
\end{tabular}

\section{INTRODUCTION}

Design and synthesis of nonsteroidal anti-inflammatory drugs (NSAIDs) is the important field in drug design, hence in recent years the newer strategy of synthesizing molecules for the inhibition of enzyme leading to inflammation is of special interest, PLA2 is a low molecular mass enzyme (Moeira et al., 2011) which is responsible for the release of arachidonic acid and lysophospholipid by catalyzing the hydrolysis of Sn2-ester bond of phospholipids. Arachidonic acid is precursor in the biosynthesis of eicosanoids and the lysophospholipid serves as a precursor for platelet activating factor, these products when produced in excess are responsible for chronic diseases such as cancer and autoimmune disorders (Dennis, 1997). Further, supported by extensive research and clinical evidences, it is found that pathophysiological conditions during inflammation are associated

\footnotetext{
${ }^{*}$ Corresponding Author

Shaukath Ara Khanum, Department of Chemistry, Yuvaraja's College,
} University of Mysore, Mysuru. E-mail: shaukathara@yahoo.co.in with depleting intrinsic antioxidants and generating free radicals causing oxidative stress.

Inspite, of profoundest development new molecules the urge to screen newer compounds for the development of new antioxidants which also specifically inhibit PLA2 remains constant, proenzyme in the inflammatory pathways, but the protecting cycloxygenase enzyme in gastric mucosa unlike the currently available nonsteroidal anti-inflammatory drugs and also bearing antioxidant property.

The broad spectrum of biological application of salicylic acid and its ester (acetyl salicylic acid and methyl salicylate) has fueled up the researchers in synthesizing organic molecules comprising of salicylic acid. Further, the pyrazolines are class of heterocyclic core which is known for its wide range of biological efficacies like anti-microbial (Karthikeyan et al., 2007; Hassan, 2013; Zitouni et al., 2005), anti-inflammatory, (Reshma and Nevagi, 2014), antidepressant (Palaska et al., 1996) and anticancer (Havrylyuk et al., 2009) etc. Numerous drugs like phenazone (1), metamizole (2) aminopyrine (3) and celecoxib (4) are available in the present market comprised of pyrazoline derivatives. 
<smiles>Cc1cc(=O)n(-c2ccccc2)n1C</smiles>

Phenazone

(1)<smiles>Cc1c(N(C)C)c(=O)n(-c2ccccc2)n1C</smiles>

Aminophenazone (3)

Bearing the above observations in mind, we have made an emphasis on synthesizing a salicylic acid integrated pyrazoline analogues and screening them for their antioxidant and phospholipase A2.

\section{EXPERIMENTAL PROTOCOLS}

\section{Chemistry}

\section{Materials and methods}

The Materials and methods are clearly discussed in earlier reference (Naveen et al., 2017).

\section{SYNTHESIS}

Synthesis of the compounds $\mathbf{7 a - j}$ were clearly discussed earlier (Naveen et al., 2017), to a stirring solution of compound 5 a $(1.8 \mathrm{mmol})$ in absolute alcohol, compound $6 \mathbf{6}(1.9 \mathrm{mmol})$, was added followed by chloramines-T $(2 \mathrm{mmol})$ the reaction mixture was refluxed on water bath. Further, the completion of the reaction was checked by TLC, the reaction mass was concentrated by evaporating the solvent, the reaction mass was dissolved in dichloromethane and the product was extracted by $10 \%$ sodium bicarbonate solution. The sodium bicarbonate extract was neutralizing with 5\% hydrochloric acid to achieve compound 7a as solid, which was further purified by column chromatography on silica gel using petroleum ether and methanol as an eluent, compounds $\mathbf{7 b}$-j was synthesized by similar method.

\section{BIOLOGY}

\section{Antioxidant assays}

\section{DPPH radical scavenging assay}

The antioxidant potential of the synthesized compound was noted through free radical scavenging assay with slightly modified method of Manzocco et al., various concentrations of the synthesized compounds, ranging from 25 to $100 \mu \mathrm{mole} / \mathrm{ml}$ in methanol was added to $4 \mathrm{ml}$ of $0.004 \%(\mathrm{w} / \mathrm{v})$ of DPPH, prepared<smiles>Cc1c(N(C)CS(=O)(=O)O)c(=O)n(-c2ccccc2)n1C</smiles>

Metamizole

(2)<smiles>Cc1cc(C(F)(F)F)nn1-c1ccc(S(N)(=O)=O)cc1</smiles>

\section{Celecoxib}

(4)

in methanol (Scherer and Godoy, 2009). The resulting mixture was incubated for $20 \mathrm{~min}$ at room temperature, and the absorbance was measured at $517 \mathrm{~nm}$ against a blank. The effective free radical scavenging activity was measured as the decrease in the absorbance of DPPH and calculated using the following equation

Percentage of scavenging $=1-($ Absorbance sample $(517$ $\mathrm{nm}) /$ Absorbance control $(517 \mathrm{~nm})) \times 100$.

Nitric oxide radical scavenging assay

The title compounds were examined for Nitric oxide radical scavenging assay (Marcocci et al., 1994), the sodium nitroprusside $(5 \mathrm{mM})$ in aqueous solution at physiological $\mathrm{pH}$, spontaneously produces nitric oxide, thus produced nitric oxide reacts with oxygen to generate nitrite ions that can be measured by Griess reagent. Nitric oxide scavengers compete with oxygen leading reduced production of nitric oxide. Sodium nitroprusside $(5 \mathrm{mM})$ in PBS was mixed with the synthesized compounds and kept at $25^{\circ} \mathrm{C}$ for 2 hours. The above samples were treated with Griess reagent ( $1 \%$ sulphanilamide, $0.1 \%$ napthylethylenediamine dihyrdochlorid and $2 \%$ orthophosphoric acid). The diazotization of nitrite with sulphanilamide and subsequent coupling with napthylethylenediamine results in the formation of chromophore with an absorbance at $540 \mathrm{~nm}$ and referred to the absorbance of standard solutions of BHT treated in the same way with Griess reagent. The radical scavenging activity was measured using the equation as described for DPPH assay.

Ferrous ion chelating assay

Ferrous ion chelating activity was recorded according to the method of Suter and Richtes (Gordon et al., 1990). Control was prepared by adding $\mathrm{FeCl}_{3}(200 \mathrm{mM})$ and $\mathrm{K}_{3} \mathrm{Fe}(\mathrm{CN})_{6}(400$ $\mathrm{mM}$ ) and the volume was made to $1 \mathrm{ml}$ using water. EDTA (40 $\mathrm{mM}$ ) was used as positive control in the other set of reactions. Title compounds of different concentrations ranging from 2 to 10 $\mu \mathrm{g} / \mathrm{mL}, \mathrm{FeCl}_{3}(200 \mu \mathrm{M})$ and $\mathrm{K}_{3} \mathrm{Fe}(\mathrm{CN})_{6}(400 \mathrm{mM})$ were added. $\mathrm{BHT}$ was used as the reference compound. The tubes were kept for $10 \mathrm{~min}$ at room temperature and optical density was measured 
at $700 \mathrm{~nm}$. The ion chelating activity was found by using formula as described for DPPH radical scavenging assay.

Hydroxyl radical scavenging assay

Hydroxyl radical scavenging assay of the synthesized compounds (Halliwell et al., 1987) was done by incubating the pyrazoline analogues with $\mathrm{H}_{2} \mathrm{O}_{2}(1 \mathrm{mM})$, deoxyribose $(2.8$
$\mathrm{mM}$ ), EDTA, $\mathrm{FeCl}_{3}$ and ascorbic acid in phosphate buffer 0.02 $\mathrm{M}, \mathrm{pH} 7.4$ for 1 hour at $37^{\circ} \mathrm{C} .1 \%$ TBA was added to quench the reaction. The tubes were boiled in water bath for $20 \mathrm{~min}$. The optical density was measured at $535 \mathrm{~nm}$ using a suitable reagent blank. The \% radical scavenging activity was done using the formula as described for DPPH scavenging assay.

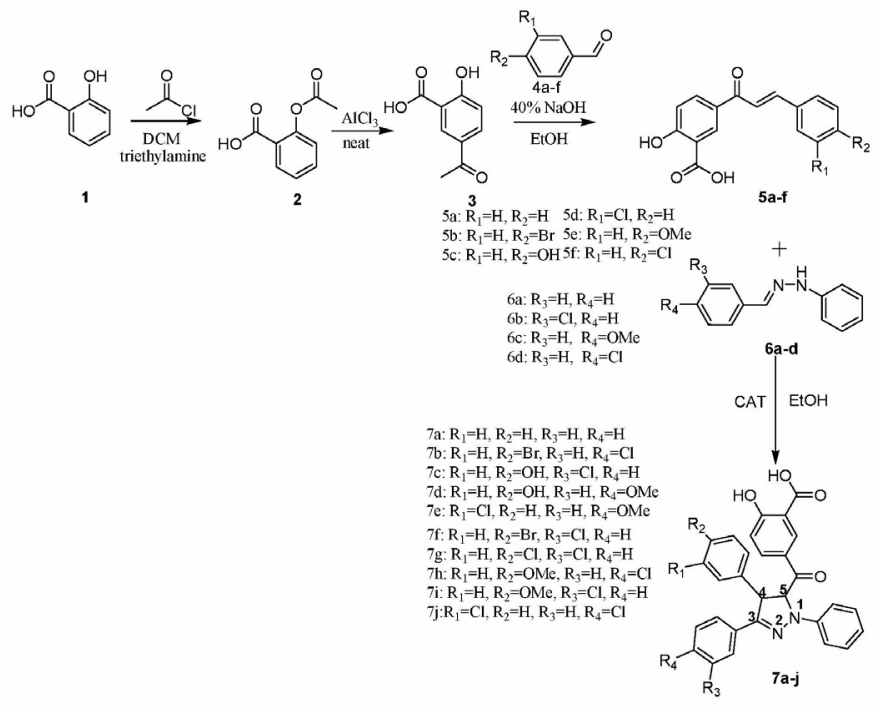

Scheme 1: Synthesis of N-phenyl-3,4bis pheny1-5(3-hydroxy-4-carboxybenzoy14,5-dihydro-pyrazoline (7a-j).

\section{Anti-inflammatory activity by inhibition of PLA2}

Protein concentration in the Russel viper venom was calculated (Lowry et al., 1957), using bovine serum albumin fraction $(0-75 \mu \mathrm{g})$. PLA2 inhibition activity was calculated by (Boman et al., 1957). Indirect hemolytic assay, a semi quantitative method was employed. Briefly, egg yolk, packed human erythrocytes and phosphate buffer saline was mixed (1:1:8 V/V). $1 \mathrm{ml}$ of this as substrate was incubated with $60 \mu \mathrm{g}$ of enzyme which was pretreated with various concentration title compounds for $30 \mathrm{~min}$ at room temperature. $9 \mathrm{ml}$ of cold phosphate buffer saline was added to stop the reaction and centrifuged at $4{ }^{\circ} \mathrm{C}$ for $10 \mathrm{~min}$ at $1500 \mathrm{rpm}$. The released hemoglobin in the supernatant was measured at $540 \mathrm{~nm}$. The assay was also performed in the presence of various concentrations $3,6,9,12$ and $15 \mu \mathrm{g} / \mathrm{ml}$ of test compound, and the percent enzyme inhibition was calculated.

\section{RESULTS AND DISCUSSION}

\section{Chemistry}

The synthesis of 5-(3-phenylacryloyl)-2hydroxybenzoic acid analogues (5a-f) is outlined in Scheme 1. 5-Acetyl-2-hydroxybenzoic acid (3) was obtained by acetylating (Kodela et al., 2011) salicylic acid (1), followed by Fries rearrangement (Prashanth et al., 2013) of 2-acetoxybenzoic acid (2) in the presence of anhydrous aluminum chloride. Compound 3 on condensing with corresponding aromatic aldehydes (4a-f) in the presence of strong base furnished (Naveen et al., 2016) 5-(3-phenylacryloyl)2-hydroxybenzoic acid (5a-f) in excellent yield. 2-Benzylidene-1-phenylhydrazine analogues (6a-d) were synthesized by reported method (Sun et al., 1996). The title compounds $\mathbf{7 a - j}$ were obtained as reported in our previous literature (Naveen et al., 2017) as represented in Scheme 1, by oxidization of compounds $\mathbf{7 a - d}$ to nitrilimines by chloramine $\mathrm{T}$ followed by 1,3-dipolar cycloaddition with compounds (5a-f).

\section{Pharmacological screening}

\section{Anti-inflammatory activity (PLA2 inhabition)}

The synthesized compound $\mathbf{7 d}$, with para hydroxy and methoxy group (Alam et al., 2016) substitution to the phenyl ring at $3^{\text {rd }}$ and $4^{\text {th }}$ position of the heyerocyclic ring, compound 7h, with chloro and methoxy groups (Geronikaki and Gavalas, 2006) at para position of the phenyl ring at $3^{\text {rd }}$ and $4^{\text {th }}$ position, $7 \mathbf{i}$ with chloro at meta and methoxy at para position at the phenyl ring at $3^{\text {rd }}$ and $4^{\text {th }}$ position respectively and $7 \mathbf{a}$ compound with no substitution showed maximum inhibition with $\mathrm{IC}_{50}$ value of $0.020,0.019,0.018$ and $0.015 \mu \mathrm{mole} / \mathrm{mL}$ respectively which is followed by compound $\mathbf{7} \mathbf{j}$, having chloro group at para position of the phenyl ring attached to $3^{\text {rd }}$ and $4^{\text {th }}$ position, compound $7 \mathbf{b}$ bearing chloro and bromo group at para to the phenyl ring attached to $3^{\text {rd }}$ and $4^{\text {th }}$ position and compound $7 \mathbf{f}$ with chloro at meta and hydroxy to para position of phenyl ring attached to $3^{\text {rd }}$ and $4^{\text {th }}$ position of heterocyclic moiety showed moderate inhibition with an $\mathrm{IC}_{50}$ values of $0.022,0.025$ and $0.024 \mu$ mole $/ \mathrm{mL}$ respectively. Compounds $7 \mathrm{c}, 7 \mathrm{e}$ and $\mathbf{7 g}$ showed least potency with $\mathrm{IC}_{50}$ values of $0.026,0.027$ and $0.027 \mu$ mole $/ \mathrm{mL}$ respectively. 


\section{Antioxidant assays}

The title compounds $\mathbf{7 a - j}$ are screened for their in vitro antioxidant activity by DPPH (Di(phenyl)-(2,4,6-trinitrophenyl) iminoazanium) radical scavenging, nitric oxide radical scavenging, ferrous ion chelating and hydroxyl radical scavenging assays, which are represented in Table 1. Compound $\mathbf{7 d}$ with para hydroxy and methoxy groups substitution (Burguete et al., 2007) at phenyl ring attached to $3^{\text {rd }}$ and $4^{\text {th }}$ position of heterocyclic ring, 7f bearing chloro group at meta position and hydroxyl substitutions at the para position of phenyl ring attached to $3^{\text {rd }}$ and $4^{\text {th }}$ position of heterocyclic ring respectively and compound $\mathbf{7 h}$ with chloro and methoxy groups both para to the phenyl ring at $3^{\text {rd }}$ and $4^{\text {th }}$ position of heterocyclic ring has shown significant antioxidant activity Compound $\mathbf{7 a}$ with no substitution, $\mathbf{7 b}$ with chloro and bromo group at para position of phenyl ring attached to $3^{\text {rd }}$ and $4^{\text {th }}$ position of heterocyclic ring respectively, $7 \mathrm{c}$ bearing chloro at meta position of phenyl ring attached to $3^{\text {rd }}$ position and bromo group substituted to para position of phenyl ring of $4^{\text {th }}$ position, 7e bearing chloro group at meta and para position of phenyl ring at $3^{\text {rd }}$ and $4^{\text {th }}$ position respectively, $\mathbf{7 g}$ with chloro substitution at para and meta position of phenyl ring at $3^{\text {rd }}$ and $4^{\text {th }}$ position of the heterocyclic ring, $7 \mathbf{i}$ with chloro substitution at meta position and methoxy at para position of the phenyl ring attached at $3^{\text {rd }}$ and $4^{\text {th }}$ position of the heterocyclic ring and $7 \mathbf{j}$ bearing chloro substitutions at the para position of phenyl ring attached to $3^{\text {rd }}$ and $4^{\text {th }}$ position of heterocyclic ring showed moderate activity in comparison with the standard BHT (2,6-di-tert-butyl-4-methyl phenol).

Table 1: Antioxidant and Anti-inflammatory activity of synthesized compounds.

\begin{tabular}{|c|c|c|c|c|c|}
\hline \multirow[t]{3}{*}{ Compound } & \multicolumn{4}{|c|}{ Antioxidant } & Anti-inflammatory \\
\hline & \multicolumn{5}{|c|}{$\mathrm{IC}_{50}$ value $(\mu \mathrm{mole} / \mathrm{mL})$} \\
\hline & DPPH & NO & FIC & HO & PLA2 Inhabition \\
\hline $7 a$ & NI & 0.017 & 0.045 & 0.0016 & 0.025 \\
\hline $7 b$ & 0.104 & $\mathrm{NC}$ & 0.089 & 0.0021 & 0.022 \\
\hline $7 \mathrm{c}$ & 0.079 & 0.018 & 0.023 & 0.0017 & 0.026 \\
\hline $7 d$ & 0.072 & 0.012 & 0.012 & 0.0015 & 0.02 \\
\hline $7 e$ & NI & 0.018 & 0.034 & 0.0013 & 0.027 \\
\hline $7 f$ & 0.071 & 0.012 & 0.013 & 0.0017 & 0.024 \\
\hline $7 \mathrm{~g}$ & 0.091 & 0.018 & 0.018 & 0.0027 & 0.027 \\
\hline $7 \mathrm{~h}$ & 0.075 & 0.011 & 0.017 & 0.0023 & 0.019 \\
\hline $7 \mathbf{i}$ & NI & 0.013 & 0.018 & 0.0021 & 0.018 \\
\hline $7 \mathbf{j}$ & NI & 0.017 & 0.018 & 0.0018 & 0.015 \\
\hline BHT & 0.163 & 0.043 & 0.045 & 0.0045 & - \\
\hline
\end{tabular}

DPPH: DPPH radical scavenging assay; NO: Nitric oxide radical scavenging assay; FIC: Ferrous ion chelating assay; HO: Hydroxyl radical scavenging assay; NC: Not chelating; NI: No inhibition.

\section{CONCLUSION}

In this present study we have the synthesized the series of salicylic acid integrated dihydropyrazoline analogous (7a-j), which were then evaluated for PLA2 inhibition as well as anti-oxidant activity. All the molecules have exhibited good anti-oxidant activity and in addition the study reveals that the compounds with donating substitution have shown excellent anti-oxidant activity, whereas the compounds with hydroxy and chloro groups have shown good PLA2 enzyme inhibition, which opens up for the further study of the synergetic effect of the two biologically potent molecules for the discovery of new bioactive molecules.

\section{ACKNOWLEDGMENTS}

Naveen P., acknowledges UGC MRP(S)-0551-13-14/ KAMY013/UGC-SWRO for the financial support. Dr. Shaukath. Ara. Khanum is thankful for financial support provided by the VGST, Government of Karnataka, under the scheme CISEE (VGST/CISEE/2012-13/2882). And also the authors are thankful to the Principal, Yuvaraja's College and JSS College of Arts, Commerce and Science, Mysouru for providing laboratory facilities.

\section{REFERENCES}

Alam MI, Alam MA, Alam O, Nargotra A, Taneja SC, Koul S. Molecular modeling and snake venom phospholipase A2 inhibition by phenolic compounds: Structure-activity relationship. Eur J Med Chem, 2016; 114:209-19.

Boman HG, and Kaletta U. Chromatography of rattlesnake venom A separation of three phosphodiesterases. Biochim Biophys Acta, 1957; 24:619-631.

Burguete A, Pontiki E, Hadjipavlou-Litina D, Villar R, Vicente E, Solano B, Ancizu S, Perez Silanes S, Aldana I, Monge A. Synthesis and anti-inflammatory/antioxidant activities of some new ring substituted 3-phenyl-1-(1,4-di-N-oxide quinoxalin-2-yl)-2-propen-1-one derivatives and of their 4,5-dihydro-(1H)-pyrazole analogues. Bioorg Med Chem Lett, 2007; 17:6439-43.

Dennis EA. The growing phospholipase A2 superfamily of signal transduction enzymes. Trends Biochem Sci, 1997; 22:1-2.

Geronikaki AA, Gavalas AM. Antioxidants and inflammatory disease: synthetic and natural antioxidants with anti-inflammatory activity. Comb Chem High Throughput Screen, 2006; 6:425-42.

Gordon $\mathrm{MH}$, The mechanism of the anti-oxidant action in vitro, BJF Hudson (ed.), Food anti-oxidants. Elsevier applied science, London New York, 1990; 1-18.

Hassan SY. Synthesis, antibacterial and antifungal activity of some new pyrazoline and pyrazole derivatives. Molecules. 2013; 28:711-732.

Halliwell B, Gutteridge JM, Aruoma OI. The deoxyribose method: a simple "test-tube" assay for determination of rate constants for reactions of hydroxyl radicals. Anal Biochem. 1987; 165:215-19.

Havrylyuk D, Zimenkovsky B, Vasylenko O, Zaprutko L, Gzella A, Lesyk R. Synthesis of novel thiazolone-based compounds containing pyrazoline moiety and evaluation of their anticancer activity. Eur J Med Chem. 2009; 44:1396.

Karthikeyan MS, Holla BS, Kumari NS. Synthesis and antimicrobial studies on novel chloro-fluorine containing hydroxy pyrazolines. Eur J Med Chem. 2007; 42:30-36.

Kodela R, Chattopadhyay M, Nath N, Lucyna, Cieciura Z, Pospishill L, Boring D, James A, Crowell, Kashfi K, Synthesis and biological activity of acetyl-protected hydroxybenzyl diethyl phosphates (EHBP) as potential chemotherapeutic agents. Bioorg Med Chem Lett, 2011; 21:7146-7150.

Lowry OH, Rosebrough NJ, Farr AL Randall RJ, Protein measurement with the Folin phenol reagent. J Biol Chem, 1951; 193:265.

Marcocci L, Maguire JJ, Droy-Lefaix MT, Packer L, The nitric oxide-scavenging properties of Ginkgo biloba extract. Biochem Biophys Res Commun, 1994; 201:748-55.

Moreira V, Gutierrez JM, Amaral RB, Lomonte B, Purgatto E, Teixeira C. A phospholipase A2 from Bothrops asper snake venom activates neutrophils in culture: expression of cyclooxygenase- 2 and $\mathrm{PGE}_{2}$ biosynthesis. Toxicon, 2011; 57:288-296.

Naveen P, Kumar G, Al-Ghorbani M. Synthesis and biological evaluation of salicylic acid conjugated isoxazoline analogues 
on immune cell proliferation and angiogenesis. Eur J Med Chem, 2016; 114:153-161.

Naveen P, Rekha, ND, Lakshmi Ranganatha, V, Begum, B. Khanum S A. Synthesis of Salicylic acid fused dihydropyrazole analogues and their mechanism of action on Escherichia coli cells. der pharma chemica, 2017; 16:91-97.

Palaska E, Erol D, Demirdamar R. Synthesis and antidepressant activities of some 1,3,5-triphenyl-2-pyrazolines, Eur J Med Chem. 1996; 31:43-47.

Reshma J, Nevagi. Recent advances in bioactive pyrazole scaffold - Part II: Anti-Inflammatory agents. Der Pharmacia Lettre, 2014; $6: 274-284$.

Sun B, Adachi K, Noguchi M, Intramolecular 1,3-Dipolar Cycloaddition at the Periphery of Heterocyclic Systems. A Facile Hydrazone-Azomethine Imine lsomerization at the Periphery of Pyridine and Pyrido[1,2-a]pyrimidine Systems. Tetrahedron, 1996; 52:901-914.

Scherer R, Godoy HT. Antioxidant activity index (AAI) by 2, 2-diphenyl-1-picrylhydrazyl method. Food Chem, 2009; 112:654-58.

Sih WB, Blakeman JC, and Mcgrath JP. Omeprazole, a specific inhibitor of gastric $(\mathrm{H}+-\mathrm{K}+)$-ATPase, is a $\mathrm{H}+$-activated oxidizing agent of sulfhydryl groups. J Biol Chem, 1985; 260:4591-4597.

Zitouni GT, Ozdemir AK, Guven. Synthesis of some 1-[(N,
N-disubstituted thiocar bamoylthio)acetyl]-3-(2-thienyl)-5-aryl-2pyrazoline derivatives and investigation of their antibacterial and antifungal activities. Arch Der Pharm, 338 (2005) 96-104

Moreira V, Gutierrez JM, Amaral RB, Lomonte B, Purgatto E, Teixeira C. A phospholipase A 2 from Bothrops asper snake venom activates neutrophils in culture: Expression of cyclooxygenase-2 and PGE 2 biosynthesis. Toxicon. 2011; 28:57 288-296.

Prashanth T, Ranganatha VL, Naveen P, Gurupadaswamy HD, Begum AB, Al-Ghorbani M, Khanum SA. Synthesis of (4-benzoylphenoxy)-acetic acid derivatives and their efficacy as antioxidant agents. Free Rad and Antiox. 2013; 3:50-54.

Lowry OH, Rosebrough NJ, Farr AL, Randall RJ, Protein measurement with the Folin phenol reagent. J. Biol. Chem.1951; 193:265-215.

How to cite this article:

Puttaswamy N, Rekha ND, Lakshmi Ranganatha V, Prashanth T, Khanum SA. Anti-inflammatory and antioxidant activity of salicylic acid conjugated dihydropyrazoline analogues. J App Pharm Sci, 2018; 8(02): 060-064. 